\title{
Preoperative embolization in patients with metastatic spinal cord compression: mandatory or optional?
}

\author{
Chul Gie Hong ${ }^{1}$, Jae Hwan Cho ${ }^{2 *}$, Dae Chul Suh ${ }^{3}$, Chang Ju Hwang ${ }^{2}$, Dong-Ho Lee ${ }^{2}$ and Choon Sung Lee ${ }^{2}$
}

\begin{abstract}
Background: The contribution of preoperative embolization in reducing intraoperative blood loss and its clinical importance are unclear. So, we aimed to compare the perioperative clinical outcomes based on whether preoperative embolization was performed and assess the role and safety of preoperative embolization in metastatic spinal cord compression (MSCC) patients.

Methods: We enrolled 52 patients (men, 37; women, 15) who underwent palliative decompression for MSCC. Demographic data, neurologic status, surgery-related data (operation time, estimated blood loss, and transfusion), complications, and survival time were recorded. Patients were categorized based on whether they received preoperative embolization: groups $\mathrm{E}$ (embolization) $(n=18)$ and NE (non-embolization) $(n=34)$ and the clinical parameters were compared. Subgroup analysis was performed specifically for cases of hypervascular tumors (23/52, 44\%).

Results: The transfusion degree was greater in the NE group ( 4.6 pints) than in the E group ( 2.5 pints, $P=0.025$ ); the other parameters did not differ between the groups. However, massive bleeding (>2000 mL) was more frequent in the NE group (10/34) than in the E group $(0 / 18, P=0.010)$. Subgroup analysis indicated that intraoperative blood loss was greater in the NE group (1988 mL) than in the E group $(1095 \mathrm{~mL}, P=0.042)$ in hypervascular tumor patients. Although massive bleeding was more frequent among hypervascular tumor patients, 3 patients with non-hypervascularized tumors also exhibited massive bleeding $(P=0.087)$.

Conclusions: Intraoperative blood loss and perioperative transfusion can be reduced by preoperative embolization in MSCC patients. Neurologic recovery, operation time, and complications did not differ according to the application of embolization. As preoperative embolization is relatively safe and effective for controlling intraoperative bleeding without any neurologic deterioration, it is highly recommended for hypervascular tumors. Moreover, it may also be effective for non-hypervascular tumors as massive bleeding may be noted in some cases.
\end{abstract}

Keywords: Embolization, Metastasis, Spine, Cord compression, Hypervascular tumor

\section{Background}

Metastatic spinal cord compression (MSCC) is a critical problem for patients with spinal metastasis. MSCC is reportedly observed in 5-10\% of cases with advanced cancer [1]. It is important to diagnose MSCC in the early period to avoid neurologic deficits. However, studies have found that $48 \%$ of patients are unable to walk at the time of diagnosis [1]. The treatment of MSCC depends on the

\footnotetext{
* Correspondence: doctork78@hanmail.net

${ }^{2}$ Department of Orthopedic Surgery, Asan Medical Center, University of Ulsan College of Medicine, 388-1, PungNap-2-dong, SongPa-gu, Seoul, Korea

Full list of author information is available at the end of the article
}

primary tumor, neurologic status, progression of limb weakness, tumor burden, performance status, life expectancy, and possibility of other therapeutic options such as radiotherapy [2-6]. No definite guidelines for MSCC treatment are available. In general, palliative decompressive surgery could be considered in cases where progressive neurologic deficit is observed, physical activity is relatively good, and multiple metastasis has been proven. Moreover, the need for surgical treatment is increasing, as longer associated survival is expected and the surgical technique has been well studied [7]. 
Palliative decompression surgery for MSCC is associated with problems such as potential massive bleeding and postoperative complications [8]. Several authors have suggested that preoperative embolization could reduce intraoperative blood loss in cases of hypervascular tumors and could thus simplify the operative procedures [9-11]. However, some studies have indicated that the blood loss does not differ when embolization is performed in cases of non-hypervascular tumors [12, 13]. Moreover, the risk of cord infarction or progression of the neurologic status as a result of operative delay are concerns related to the preoperative embolization procedures. Hence, the clinical benefits and risks of preoperative embolization need to be carefully evaluated, particularly in non-hypervascular tumors. To our knowledge, no definitive conclusion or guideline has been established with regard to the clinical importance of preoperative embolization.

In the present study, we aimed to compare the perioperative clinical outcomes based on whether preoperative embolization is performed in patients with MSCC and to assess the role and safety of preoperative embolization.

\section{Methods}

\section{Patients and clinical parameters}

We enrolled a total of 52 consecutive patients (37 men and 15 women) who underwent palliative decompression for MSCC from March 2012 to December 2014 at a single center. Demographic data, neurologic status, surgery-related data (operation time, estimated blood loss, and transfusion), complications, and survival time were recorded from the electronic medical records at our institution. The neurologic status was assessed based on the motor strength of the lower extremity: grade 0 , no muscle contraction; grade 1 , minimal muscle contraction; grade 2, active movement under gravity-free conditions; grade 3, active movement under gravity; grade 4, active movement under limited resistance; and grade 5 , no weakness. If the values differed between the right and left lower extremities, the average values were adopted for analysis. The performance status was assessed using the Karnofsky performance status scale. The degree of tumor involvement was assessed by Bilsky scale [14]. The degree of instability was evaluated by Spinal Instability Neoplastic Score (SINS) [15]. Operation time was measured from skin incision to closure. Intraoperative blood loss was estimated based on the difference in the volume of suction drainage and irrigation fluid. The degree of transfusion was determined according to the use of packed red blood cells (RBC). The complications included surgical (hematoma, infection, or wound dehiscence) and medical (pneumonia, cardiac problem, or sudden death) problems. Although angiography was performed to assess hypervascularity as far as possible, we did not perform angiography because of the following reasons in many cases: (1) rapid progression of neurologic deficit, (2) lack of support such as absence of interventional radiologists, and (3) surgeon's judgment after consideration of risk and benefit of embolization. Patients were categorized based on whether they underwent preoperative embolization: group E (embolization) and group NE (non-embolization). The clinical parameters were compared between the two groups. Subgroup analysis was performed specifically in the cases of hypervascular tumors (hepatocellular carcinoma, renal cell carcinoma, and thyroid cancer).

\section{Embolization procedure}

Embolization was performed by radiologists with the patient under local anesthesia. A 4-F or 5-F catheter was used to perform diagnostic angiography. Angiography of the vertebral arteries, segmental arteries, and feeding branches supplying the tumors was performed. Thereafter, embolization with polyvinyl alcohol (PVA) particles and/or gelatin sponge (Gelfoam) was performed. If the branches supplying the tumors could be approached directly, then the particles were infused by introducing a microcatheter. If these branches could not be approached, then the normal branches distal to the feeder were protected by Gelfoam or coil prior to the infusion of particles. If the feeding vessels were too small to be identified, embolization was not performed. Repeat angiography was performed immediately to confirm residual tumor staining after embolization. An example of the embolization procedure is shown in Fig. 1.

\section{Surgical procedure}

Surgery was performed within $48 \mathrm{~h}$ after embolization. Instrumentation was performed using pedicle screws and rods across two levels, above and below the lesion. Thereafter, posterior decompression with total laminectomy was performed. Additional tumor resection was performed in certain cases. However, corpectomy of the vertebral body via the transpedicular approach or anterior approach was not performed. Bone grafting was also not routinely performed because of the short-term life expectancy of the patients. Two suction drains were placed after careful hemostasis. An example of a surgical case in a patient with MSCC is shown in Fig. 2.

\section{Statistical analyses}

The demographic and operation-related parameters were compared between the two groups by using the independent $t$ test, Mann Whitney $U$ test, chi-square test, or Fisher's exact test. Survival analysis was conducted with the Kaplan-Meier method and log-rank test. All statistical analyses were performed using the Statistical Package for the Social Sciences version 21.0 (SPSS Inc., Chicago, IL); $P$ values $<0.05$ were considered to be statistically significant. 


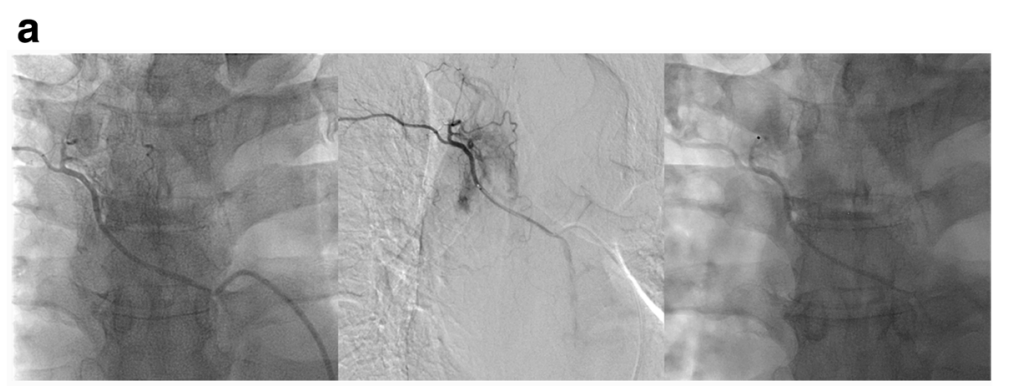

b

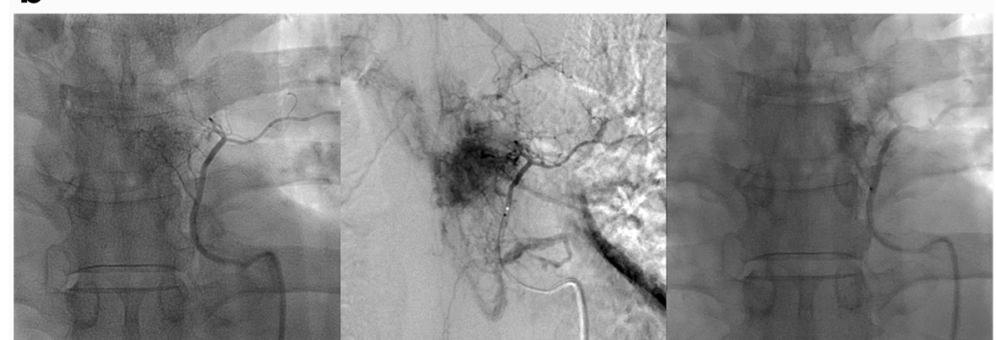

Fig. 1 Angiography and embolization procedure in a 52-year old HCC patient with MSCC at T6. a Angiogram at the left 6th intercostal artery was obtained (left), hypervascular staining was observed (middle), and embolization was successful (right). b The same procedure was repeated at the right 6th intercostal artery. Hepatocellular carcinoma (HCC), metastatic spinal cord compression (MSCC)
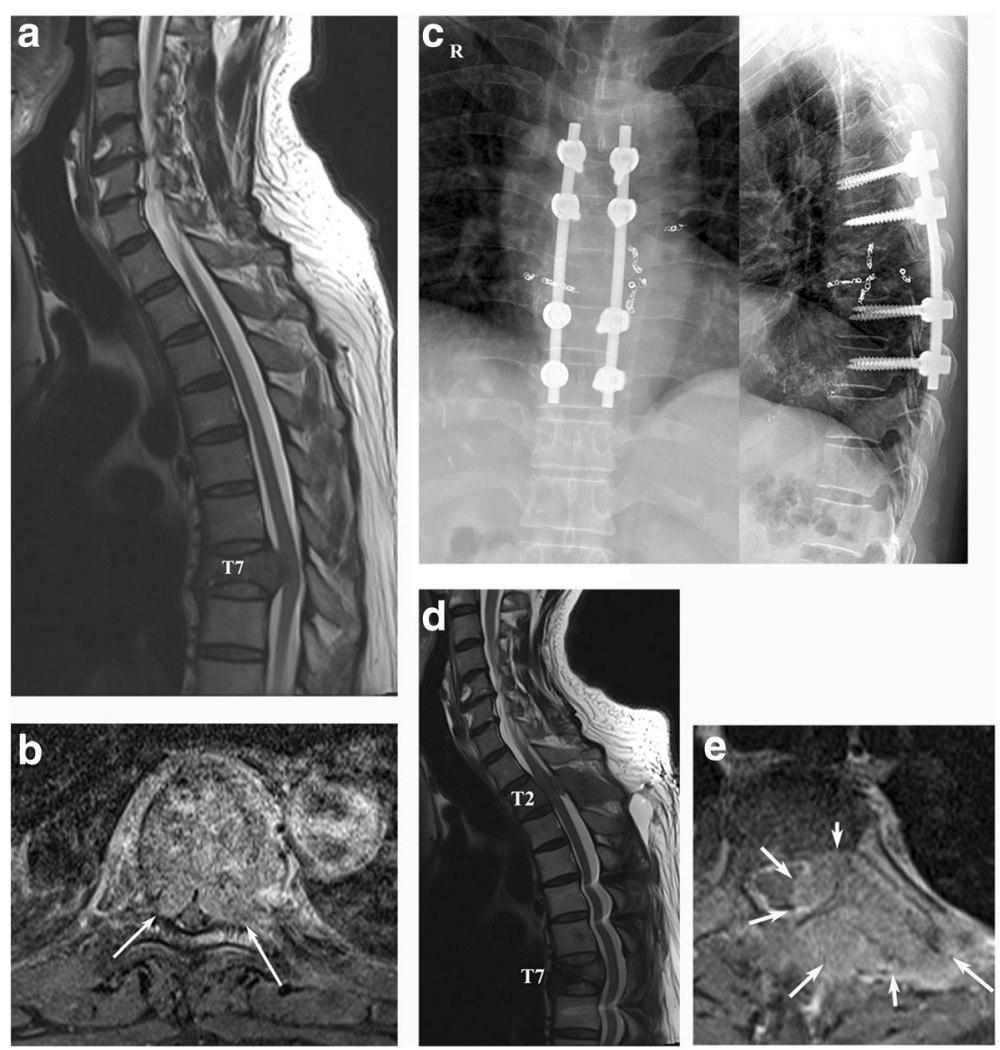

Fig. 2 A 54-year old man with HCC who developed MSCC. a Preoperative T2-weighted sagittal MR image showing cord compression at T7. b Preoperative T1-weighted enhanced MR image (arrows indicate cord compression by the tumor mass). c Postoperative radiographs. $\mathbf{d}$ T2-weighted sagittal MR image 6 months postoperatively showing another occurrence of cord compression at T2, with maintenance of the decompression at T7. e T1-weighted enhanced MR image at T2 (arrows indicate tumor mass). Hepatocellular carcinoma (HCC), metastatic spinal cord compression (MSCC) 


\section{Results}

\section{Demographic data}

The mean patient age at the time of operation was $59.7 \pm$ 12.3 years. The most common origin of the cancers was hepatocellular carcinoma (HCC) $(n=12,23.1 \%)$, followed by renal cell carcinoma (RCC) $(n=10,19.2 \%)$ and lung cancer $(n=9,17.3 \%)$. The most commonly involved sites were T6 $(n=9)$ and T7 $(n=10)$, followed by T3 $(n=8)$ and T4 $(n=7)$. The estimated blood loss was $1.22 \pm$ $0.95 \mathrm{~L}$, and the mean degree of transfusion was $3.9 \pm$ 4.2 pints. The operation time was $198 \pm 54 \mathrm{~min}$.

\section{Preoperative embolization}

Of the 52 study patients, 24 (46.2\%) underwent preoperative angiography. However, 6 patients did not undergo embolization due to the presence of small arteries $(n=3)$, risk of cord infarction $(n=2)$, and difficulty with accessibility due to the presence of markedly tortuous vessels $(n=1)$. Thus, 18 patients $(34.6 \%)$ underwent preoperative embolization. The involved vessels were segmental arteries or intercostal arteries that supply the tumors. No procedure-related complications were observed in 18 cases. Complete or near-complete (>80\%) embolization was possible in 13 cases (72.2\%). Partial embolization was performed in the other 5 cases due to the risk of cord ischemia or an inaccessible location. The time period between embolization and the surgical procedure was $16.4 \pm 9.1 \mathrm{~h}$.

\section{Comparisons of demographic and operation-related parameters}

Eighteen and 34 patients were assigned to groups $\mathrm{E}$ and NE, respectively. The preoperative demographic data did not significantly differ between the two groups (Table 1). However, the neurologic status in the NE group was inferior to that in the E group (2.7 vs 3.6), although the difference was not significant $(P=0.067)$. The postoperative neurologic status was also different between the two groups (2.9 vs $3.8, P=0.042$ ); however, the degree of neurologic improvement did not significantly differ $(P=0.519)$. Moreover, the degree of transfusion was greater in the NE group (4.6 pints) than in the $E$ group (2.5 pints, $P=0.025)$. Blood loss, operation time, and complications did not differ between the two groups. However, massive bleeding (>2000 $\mathrm{mL})$ was more frequent in the NE group (10/34) than in the $\mathrm{E}$ group $(0 / 18, P=0.010)$. A comparison of the intraoperative and perioperative parameters is described in Table 2.

Of the 52 patients, 23 (44\%) exhibited hypervascular tumors. A greater amount of intraoperative blood loss was observed in the cases with hypervascular tumors (1600 mL vs $916 \mathrm{~mL}, P=0.015)$. Although massive bleeding was more frequently noted in cases with hypervascular tumors, 3 patients with non-hypervascularized tumors (prostate cancer, germ cell tumor, and breast cancer) also showed massive bleeding $(P=0.087)$. The comparisons between hypervascular and non-hypervascular tumors are described in Table 3.

Subgroup analysis indicated that intraoperative blood loss was greater in the NE group $(1988 \mathrm{~mL})$ than in the E group (1095 $\mathrm{mL}, P=0.042)$ in cases of hypervascular tumors. Although $53.8 \%$ of patients in the NE group exhibited massive bleeding, none of the patients in the $\mathrm{E}$ group exhibited massive bleeding $(P=0.007)$. The results of subgroup analysis for cases of hypervascular tumors are summarized in Table 4. Subgroup analysis between HCC (12 cases) and RCC (10 cases) showed no differences in demographic data, operation-related data, and clinical outcomes. In addition, no differences according to involved levels (T1-5 vs T6-12) could be found.

\section{Perioperative complications and survival analysis}

The most common complications of palliative decompression for MSCC were pulmonary problems (7/52, $13.5 \%)$ and wound problems $(6 / 52,11.5 \%)$ including seroma formation. Four patients (7.7\%) exhibited wound dehiscence, and repeated debridement and advancement flap operations were performed by plastic surgeons.

Table 1 Demographic data of two groups classified by preoperative embolization

\begin{tabular}{llll}
\hline & Group NE $(n=34)$ & Group E $(n=18)$ & $P$ value \\
\hline Age (year) & $60.7 \pm 12.6$ & $57.7 \pm 11.6$ & 0.396 \\
Sex & M:F=21:13 & M:F =16:2 & 0.055 \\
Hypervascular tumor & $13 / 34(38.2 \%)$ & $10 / 18(55.6 \%)$ & 0.232 \\
Preop. RTx & $11 / 34(32.4 \%)$ & $7 / 18(38.9 \%)$ & 0.637 \\
Bilsky scale (Gr1:Gr2:Gr3) & $6: 11: 17$ & $2: 7: 9$ & 0.790 \\
Preop. neurologic status (Gr) & $2.7 \pm 1.7$ & $3.6 \pm 1.4$ & 0.058 \\
SINS & $8.2 \pm 2.1$ & $7.2 \pm 1.8$ & 0.070 \\
Site ( $\geq$ T5: $<$ T5) & $14: 20$ & $7: 11$ & 0.873 \\
Karnofsky performance & $64.1 \pm 14.0$ & $71.7 \pm 12.0$ & 0.058 \\
\hline
\end{tabular}

Means and standard variation are shown for continuous variables, and the number of cases is shown for categorical variables

NE non-embolization, E embolization, Preop preoperative, RTX radiotherapy, SINS Spinal Instability Neoplastic Score, Gr grade 
Table $\mathbf{2}$ Intraoperative and perioperative parameters between two groups

\begin{tabular}{llll}
\hline & Group NE $(n=34)$ & Group E $(n=18)$ & $P$ value \\
\hline Postop. neurologic status (Gr) & $2.9 \pm 1.8$ & $3.8 \pm 1.3$ & 0.066 \\
Postop. neurologic improvement & $12 / 34(35.3 \%)$ & $8 / 18(44.4 \%)$ & 0.519 \\
Op. time (min) & $197.0 \pm 60.1$ & $201.2 \pm 42.1$ & 0.790 \\
Levels of laminectomy & $1.3 \pm 0.5$ & $1.2 \pm 0.5$ & 0.604 \\
EBL (L) & $1.37 \pm 1.11$ & $0.99 \pm 0.47$ & 0.098 \\
Transfusion (pint) & $4.6 \pm 4.9$ & $2.5 \pm 1.5$ & 0.025 \\
Massive bleeding & $10 / 34(29.4 \%)$ & $0 / 18(0 \%)$ & 0.010 \\
Complication & $9 / 34(26.5 \%)$ & $5 / 18(27.8 \%)$ & 0.919 \\
\hline
\end{tabular}

Massive bleeding is defined by intraoperative bleeding more than $2 \mathrm{~L}$

$N E$ non-embolization, E embolization, Postop. postoperative, Op. operation, EBL estimated blood loss, Gr grade

Another 2 patients showed postoperative hematoma; 1 patient was successfully treated via hematoma evacuation, whereas the other showed permanent neurologic deficits following hematoma evacuation. In that case, massive bleeding was observed, and blood loss persisted after surgery due to the reduced coagulative ability. After hematoma evacuation, angiography and embolization were performed to control the bleeding. The perioperative complications in the overall cohort are summarized in Table 5.

The mean estimated survival time was $14.8 \pm 5.9$ months, and the median survival time was $8.0 \pm 2.6$ months. The Kaplan-Meier survival curve is illustrated in Fig. 3. Survival did not significantly differ between the NE group and $\mathrm{E}$ group $(P=0.321)$.

\section{Discussion}

Patients with MSCC are frequently encountered in the clinical setting. Moreover, as most metastatic spinal tumors are hypervascular in nature, it is essential to focus on decreasing the intraoperative blood loss [16]. Several reports have described the usefulness of preoperative embolization in reducing intraoperative blood loss in spinal tumors [10, 17, 18]. In particular, embolization has been reported to be effective for reducing blood loss in hypervascular tumors such as $\operatorname{RCC}[9,12,18]$. However, several reports have suggested that the procedure does not decrease blood loss, and instead, care must be taken to avoid cord ischemia [19]. Furthermore, it was reported that there was no difference in blood loss between the use of local hemostatic agents and preoperative embolization [20]. Thus, no definitive guidelines regarding preoperative embolization have been established for the treatment of MSCC patients.

To determine the superiority of the routine clinical use of preoperative embolization, the assessment of the risk of the procedure is critical. In our present study, none of the patients showed procedure-related complications, including neurologic deficits. However, embolization was not performed in 2 patients because of the risk of cord infarction due to occlusion of the anterior spinal arteries. In fact, cord ischemia may be the most critical complication

Table 3 Comparisons between hypervascular and non-hypervascular tumor

\begin{tabular}{llll}
\hline & Hypervascular $(n=23)$ & Non-hypervascular $(n=29)$ & $P$ value \\
\hline Age & $55.8 \pm 10.3$ & $62.7 \pm 13.0$ & 0.043 \\
Sex & M:F $=19: 4$ & M:F $=18: 11$ & 0.132 \\
Preop. neurologic status (Gr) & $3.1 \pm 1.7$ & $2.9 \pm 1.6$ & 0.571 \\
Postop. neurologic status (Gr) & $3.2 \pm 1.7$ & $3.3 \pm 1.6$ & 0.857 \\
Bilsky scale (Gr1:Gr2:Gr3) & $5: 6: 12$ & $3: 12: 14$ & 0.370 \\
SINS & $7.7 \pm 1.9$ & $8.0 \pm 2.1$ & 0.505 \\
Karnofsky performance & $67.8 \pm 14.8$ & $65.9 \pm 13.0$ & 0.612 \\
Number of laminectomy & $1.2 \pm 0.5$ & $1.3 \pm 0.5$ & 0.553 \\
Op. time (min) & $204.6 \pm 61.7$ & $193.4 \pm 47.4$ & 0.466 \\
EBL (L) & $1.60 \pm 1.14$ & $0.92 \pm 0.64$ & 0.015 \\
Transfusion (pint) & $4.5 \pm 4.4$ & $3.4 \pm 3.9$ & 0.366 \\
Massive bleeding & $7 / 23(30.4 \%)$ & $3 / 29(10.3 \%)$ & 0.087 \\
Complication & $4 / 23(17.4 \%)$ & $10 / 29(34.5 \%)$ & 0.217 \\
\hline
\end{tabular}

Gr grade, EBL estimated blood loss, SINS Spinal Instability Neoplastic Score 
Table 4 Subgroup analysis for hypervascular tumors (HCC, RCC, and thyroid ca.)

\begin{tabular}{llll}
\hline & Group NE $(n=13)$ & Group E $(n=10)$ & $P$ value \\
\hline Preop. neurologic status (Gr) & $2.4 \pm 1.7$ & $4.0 \pm 1.4$ & 0.023 \\
Postop. neurologic status (Gr) & $2.4 \pm 1.8$ & $4.2 \pm 1.0$ & 0.006 \\
Postop. neurologic improvement & $4 / 13(30.8 \%)$ & $4 / 10(40.0 \%)$ & 0.685 \\
Op. time (min) & $208.3 \pm 78.8$ & $199.8 \pm 31.3$ & 0.790 \\
EBL (L) & $1.99 \pm 1.37$ & $1.10 \pm 0.40$ & 0.042 \\
Transfusion (pint) & $5.6 \pm 5.6$ & $3.0 \pm 1.5$ & 0.156 \\
Massive bleeding & $7 / 13(53.8 \%)$ & $0 / 10(0 \%)$ & 0.007 \\
Complication & $2 / 13(15.4 \%)$ & $2 / 10(20.0 \%)$ & 1.000 \\
\hline
\end{tabular}

Gr grade, EBL estimated blood loss

of this procedure. Based on an animal study, contiguous ligation of three segmental vessels bilaterally did not lead to any neurologic compromise [21]. However, the ligation of $>4$ levels produced ischemic cord dysfunction in a dog model [22]. Therefore, we performed embolization up to two levels bilaterally, and up to three levels unilaterally, which we considered to be safe. The safety of embolization has also been reported by several authors [10, 23, 24]. However, most of these authors also indicated the risk of cord ischemia.

The factors associated with the effectiveness of preoperative embolization remain unclear. Although it could be reasonable that less blood loss was found in cases of complete occlusion $[11,25]$, no difference in blood loss was observed according to the completeness of the occlusion $[17,23]$. In addition, the time interval may be another important parameter. Some authors proposed that preoperative embolization was effective when the time from the procedure to the index surgery was $<24 \mathrm{~h}$ [25]. In contrast, other authors did not find any correlation between the time interval and intraoperative blood loss [17]. Furthermore, as surgical timing is critical for mitigating a decline in neurologic function, a delay in the operation due to preoperative embolization may be a problem. However, in the present study, we found that none of the patients showed a progression of neurologic deficits, even though the average time interval between the procedure and the index operation was $16 \mathrm{~h}$. Nevertheless, this finding was not conclusive, as patients with more severe neurologic deficit tended to undergo surgery more promptly without embolization $(P=0.067)$.

The abovementioned controversial results could be attributed to the retrospective nature of those studies. A randomized controlled trial showed no difference in blood loss and transfusion based on whether preoperative

Table 5 Summary of perioperative complications

\begin{tabular}{|c|c|c|c|c|c|}
\hline Case & Origin & Group & EBL & Complications & Progression \\
\hline 1 & Lung cancer & NE & 1500 & Respiratory failure & Death in 1 week \\
\hline 2 & Lymphoma & NE & 1500 & Wound dehiscence & Advancement flap by plastic surgeon \\
\hline 9 & Breast cancer & NE & 2000 & Hematoma & Neurologic recovery after hematoma evacuation \\
\hline 10 & RCC & NE & 3000 & Pneumonia & Recovery after medical treatment \\
\hline 14 & Plasmacytoma & NE & 1000 & Pulmonary thromboembolism & $\begin{array}{l}\text { Recovery after insertion of IVC filter, anticoagulation } \\
\text { therapy }\end{array}$ \\
\hline 21 & $\mathrm{RCC}$ & E & 1600 & Pneumothorax & $\begin{array}{l}\text { Tracheostomy status. Expire in } 3 \text { months due to } \\
\text { respiratory failure }\end{array}$ \\
\hline 25 & Rectal cancer & E & 300 & Wound dehiscence in 1 month & Advancement flap by plastic surgeon \\
\hline 35 & $\mathrm{RCC}$ & E & 800 & Wound dehiscence & Advancement flap by plastic surgeon \\
\hline 38 & Esophageal cancer & NE & 400 & Pneumonia & Recovery after medical treatment \\
\hline 40 & Breast cancer & NE & 400 & Dural tear, seroma & Observation \\
\hline 43 & Lung cancer & E & 600 & Wound infection in 1 month & $\begin{array}{l}\text { Debridement (+). Death in } 6 \text { weeks due to respiratory } \\
\text { failure }\end{array}$ \\
\hline 50 & Klatskin tumor & E & 400 & Dural tear, wound dehiscence & Advancement flap by plastic surgeon \\
\hline 51 & myeloma & NE & 200 & Atelectasis & Recovery after chest tube insertion \\
\hline 52 & $\mathrm{HCC}$ & NE & 4000 & Neurologic deficit by hematoma, respiratory failure & $\begin{array}{l}\text { Persistent neurologic deficit after hematoma } \\
\text { evacuation }\end{array}$ \\
\hline
\end{tabular}



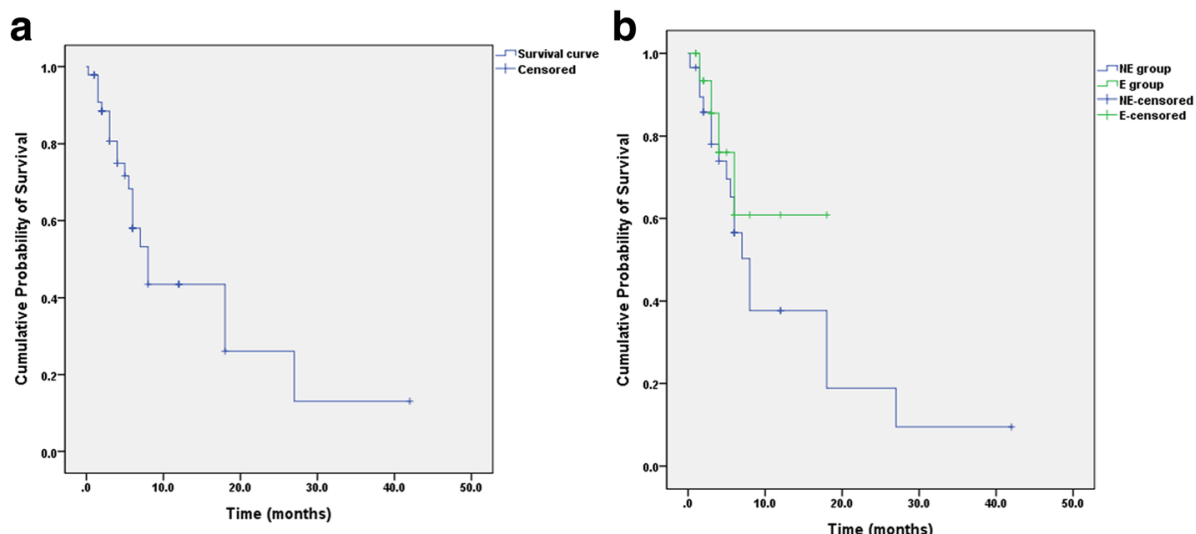

Fig. 3 Survival analysis. a Kaplan-Meier survival curve for all patients. b Comparison of the survival curve according to whether preoperative embolization was performed

embolization was performed, although the patients with preoperative embolization did exhibit a reduction in surgical time [13]. However, that study had certain limitations, such as the heterogeneity of the population in terms of differing vascularity and a relatively small sample size. An assessment of the hypervascularity of the tumors would be critical for predicting intraoperative bleeding. However, no definite tools for such an assessment have been developed thus far. In particular, MRI characteristics are not known to be reliable for determining vascularity [26]. Therefore, we believe that routine angiography could be better for identifying tumor vascularity, as it is not associated with any adverse effects such as neurologic deterioration.

The present study had certain limitations of note. First, the number of patients who underwent preoperative embolization procedures was relatively small. Hence, the effect of complete or partial occlusion of feeder arteries could not be assessed. Second, some of the tumors classified as non-hypervascular tumors might have had some extent of hypervascularity. Previous reports have stated that breast cancer or prostate cancer occasionally exhibits hypervascular features [27]. Third, although surgery was performed by a single surgeon, angiography and embolization were conducted by multiple radiologists. Hence, the completeness of the embolization could be influenced by the technique or experience of the radiologist. Fourth, selection bias should be considered, as patients with greater neurological deterioration tended to be selected for emergent operation without embolization.

Despite these limitations, however, this study showed that preoperative embolization is relatively safe and effective for reducing intraoperative blood loss in surgery for MSCC. Furthermore, preoperative embolization is critical for minimizing the probability of massive bleeding in non-hypervascular as well as hypervascular tumors.

\section{Conclusions}

In conclusion, intraoperative blood loss and perioperative transfusion can be reduced by using preoperative embolization in patients with MSCC. The neurologic recovery and complications do not differ based on whether embolization was performed. As preoperative embolization is relatively safe and effective for controlling intraoperative bleeding without any neurologic deterioration, it is highly recommended for hypervascular tumors. Furthermore, preoperative embolization can serve as a good option for non-hypervascular tumors, as massive bleeding was also found in certain cases.

\section{Acknowledgements}

The authors thank Mi Young Lee, Sungjoo Cheon, So Jung Yoon, and A Lyoun Lee for their contribution in the data collection.

\section{Funding}

This study was not supported by any kinds of funding.

\section{Availability of data and materials}

The datasets generated and analyzed during this study are available from the corresponding author on a reasonable request.

\section{Authors' contributions}

CGH and JHC designed this study and drafted the manuscript. DCS and CSL participated in the study design and coordination. CJH and DCS supported in analyzing the data. All authors read and approved the final manuscript.

\section{Competing interests}

The authors declare that they have no competing interests.

Consent for publication

Not applicable.

Ethics approval and consent to participate

This study was approved by the Institutional Review Board of Asan Medical Center, which waived the requirement for informed consent due to retrospective nature of this study. 


\section{Author details}

'Department of Orthopedic Surgery, CHA Gumi Medical Center, Cha University, Gumi, Korea. ${ }^{2}$ Department of Orthopedic Surgery, Asan Medical Center, University of Ulsan College of Medicine, 388-1, PungNap-2-dong, SongPa-gu, Seoul, Korea. ${ }^{3}$ Department of Radiology, Asan Medical Center, University of Ulsan College of Medicine, Seoul, Korea.

\section{Received: 26 October 2016 Accepted: 8 February 2017}

\section{Published online: 14 February 2017}

\section{References}

1. National Collaborating Centre for Cancer (UK): National Institute for Health and Clinical Excellence: Guidance. In metastatic spinal cord compression: diagnosis and management of patients at risk of or with metastatic spinal cord compression. Cardiff (UK): National Collaborating Centre for Cancer (UK) 2008.

2. Lei M, Li J, Liu Y, Jiang W, Liu S, Zhou S. Who are the best candidates for decompressive surgery and spine stabilization in patients with metastatic spinal cord compression (MSCC)? A new scoring system. Spine (Phila Pa 1976). 2016:41:1469-76.

3. Loblaw DA, Perry J, Chambers A, Laperriere NJ. Systematic review of the diagnosis and management of malignant extradural spinal cord compression: the Cancer Care Ontario Practice Guidelines Initiative's NeuroOncology Disease Site Group. J Clin Oncol. 2005;23:2028-37.

4. Loblaw DA, Mitera G, Ford M, Laperriere NJ. A 2011 updated systematic review and clinical practice guideline for the management of malignant extradural spinal cord compression. Int J Radiat Oncol Biol Phys. 2012;84:312-7.

5. Tomita K, Kawahara N, Kobayashi T, Yoshida A, Murakami H, Akamaru T. Surgical strategy for spinal metastases. Spine (Phila Pa 1976). 2001;26:298-306.

6. Tokuhashi Y, Matsuzaki H, Oda H, Oshima M, Ryu J. A revised scoring system for preoperative evaluation of metastatic spine tumor prognosis. Spine (Phila Pa 1976). 2005;30:2186-91.

7. Lee CS, Jung CH. Metastatic spinal tumor. Asian Spine J. 2012;6:71-87.

8. Tang B, Ji T, Tang X, Jin L, Dong S, Guo W. Risk factors for major complications in surgery for hypervascular spinal tumors: an analysis of 120 cases with adjuvant preoperative embolization. Eur Spine J. 2015;24:2201-8.

9. Griessenauer CJ, Salem M, Hendrix P, Foreman PM, Ogilvy CS, Thomas AJ. Preoperative embolization of spinal tumors: a systematic review and metaanalysis. World Neurosurg. 2016;87:362-71.

10. Nair S, Gobin YP, Leng LZ, Marcus JD, Bilsky M, Laufer I, Patsalides A Preoperative embolization of hypervascular thoracic, lumbar, and sacral spinal column tumors: technique and outcomes from a single center. Interv Neuroradiol. 2013;19:377-85.

11. Wilson MA, Cooke DL, Ghodke B, Mirza SK. Retrospective analysis of preoperative embolization of spinal tumors. AJNR Am J Neuroradiol. 2010;31:656-60.

12. Robial N, Charles YP, Bogorin I, Godet J, Beaujeux R, Boujan F, Steib JP. Is preoperative embolization a prerequisite for spinal metastases surgical management? Orthop Traumatol Surg Res. 2012:98:536-42.

13. Clausen C, Dahl B, Frevert SC, Hansen LV, Nielsen MB, Lonn L. Preoperative embolization in surgical treatment of spinal metastases: single-blind, randomized controlled clinical trial of efficacy in decreasing intraoperative blood loss. J Vasc Interv Radiol. 2015;26:402-12. e401.

14. Bilsky MH, Laufer I, Fourney DR, Groff M, Schmidt MH, Varga PP, Vrionis FD, Yamada Y, Gerszten PC, Kuklo TR. Reliability analysis of the epidural spinal cord compression scale. J Neurosurg Spine. 2010;13:324-8.

15. Fourney DR, Frangou EM, Ryken TC, Dipaola CP, Shaffrey Cl, Berven SH, Bilsky MH, Harrop JS, Fehlings MG, Boriani S, Chou D, Schmidt MH, Polly DW, Biagini R, Burch S, Dekutoski MB, Ganju A, Gerszten PC, Gokaslan ZL, Groff MW, Liebsch NJ, Mendel E, Okuno SH, Patel S, Rhines LD, Rose PS, Sciubba DM, Sundaresan N, Tomita K, Varga PP, Vialle LR, Vrionis FD, Yamada Y, Fisher CG. Spinal instability neoplastic score: an analysis of reliability and validity from the spine oncology study group. J Clin Oncol. 2011;29:3072-77.

16. Truumees E, Dodwad SN, Kazmierczak CD. Preoperative embolization in the treatment of spinal metastasis. J Am Acad Orthop Surg. 2010;18:449-53.

17. Kato S, Murakami H, Minami T, Demura S, Yoshioka K, Matsui O, Tsuchiya H. Preoperative embolization significantly decreases intraoperative blood loss during palliative surgery for spinal metastasis. Orthopedics. 2012;35:e1389-1395.

18. Manke C, Bretschneider T, Lenhart M. Strotzer M, Neumann C, Gmeinwieser J, Feuerbach S. Spinal metastases from renal cell carcinoma: effect of preoperative particle embolization on intraoperative blood loss. AJNR Am J Neuroradiol. 2001;22:997-1003
19. Qiao Z, Jia N, He Q. Does preoperative transarterial embolization decrease blood loss during spine tumor surgery? Interv Neuroradiol. 2015;21:129-35.

20. Ptashnikov D, Zaborovskii N, Mikhaylov D, Masevnin S. Preoperative embolization versus local hemostatic agents in surgery of hypervascular spinal tumors. Int J Spine Surg. 2014;8.

21. Ueda Y, Kawahara N, Tomita K, Kobayashi T, Murakami H, Nambu K. Influence on spinal cord blood flow and function by interruption of bilateral segmental arteries at up to three levels: experimental study in dogs. Spine (Phila Pa 1976). 2005:30:2239-43.

22. Kato S, Kawahara N, Tomita K, Murakami H, Demura S, Fujimaki Y. Effects on spinal cord blood flow and neurologic function secondary to interruption of bilateral segmental arteries which supply the artery of Adamkiewicz: an experimental study using a dog model. Spine (Phila Pa 1976). 2008;33:1533-41.

23. Kobayashi K, Ozkan E, Tam A, Ensor J, Wallace MJ, Gupta S. Preoperative embolization of spinal tumors: variables affecting intraoperative blood loss after embolization. Acta Radiol. 2012:53:935-42.

24. Shi HB, Suh DC, Lee HK, Lim SM, Kim DH, Choi CG, Lee CS, Rhim SC. Preoperative transarterial embolization of spinal tumor: embolization techniques and results. AJNR Am J Neuroradiol. 1999;20:2009-15.

25. Kumar N, Tan B, Zaw AS, Khine HE, Maharajan K, Lau LL, Rajendran PC, Gopinathan A. The role of preoperative vascular embolization in surgery for metastatic spinal tumours. Eur Spine J. 2016;25:3962-70.

26. Bode KS, Radcliff KE, Vaccaro AR. MRI characterization of vascular spinal tumors. J Spinal Disord Tech. 2015;28:E590-594.

27. Thiex R, Harris MB, Sides C, Bono CM, Frerichs KU. The role of preoperative transarterial embolization in spinal tumors. A large single-center experience. Spine J. 2013:13:141-9.

\section{Submit your next manuscript to BioMed Central and we will help you at every step:}

- We accept pre-submission inquiries

- Our selector tool helps you to find the most relevant journal

- We provide round the clock customer support

- Convenient online submission

- Thorough peer review

- Inclusion in PubMed and all major indexing services

- Maximum visibility for your research

Submit your manuscript at www.biomedcentral.com/submit
C) Biomed Central 